\title{
GIL VICENTE E A MÁXIMA DO AMOR AO PRÓXIMO
}

Nadiá Paulo Ferreira Universidade Estadual do Rio de Janeiro

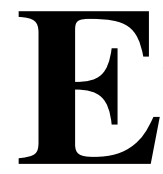

m 1502, Gil Vicente inicia sua carreira de dramaturgo, no reinado de D. Manuel, sendo nomeado por D. Leonor, viúva de D. João II e irmã de D. Manuel, o organizador dos espetáculos da corte, permanecendo nesse cargo por mais de trinta anos. Sua carreira, portanto, abrange os reinados de D. Manuel (1495-1521) e D. João III (1521-1557), onde predominava um clima de certa liberdade intelectual e artística. Em 1536, ano em que Gil Vicente desaparece do cenário português, é instalada a Santa Inquisição em Portugal. Três anos depois, em 1539, o cardeal-infante, D. Henrique, é nomeado para o cargo de inquisidor-mor. Como não podia deixar de acontecer, a censura se abate sobre a obra vicentina, proibindo algumas peças, o que fez com que algumas delas ficassem até hoje desaparecidas.

A produção vicentina se inscreve na tradição do teatro medieval, embora se situe, historicamente, no limiar, entre o fim do teatro medieval e o início do teatro renascentista. Esta inscrição faz com que o autor, praticamente, ignore todas as transformações que estão acontecendo na cultura e nas artes portuguesas, com o advento do Renascimento. A teoria aristotélica dos gêneros começa a se impor, até seus princípios se tornarem o suporte de um discurso, cuja hegemonia irá determinar não só o julgamento estético da teoria e da crítica literárias, mas também a criação das obras de arte. Do ponto de vista da estética aristotélica, a maioria de suas peças seria considerada um teatro sem unidade de ação, de tempo e de espaço. Algumas peças, como Auto da Lusitânia e Juiz da Beira, seriam, inclusive, julgadas como "gêneros menores" e, portanto, inferiores, por não apresentarem, sob o prisma da referida teoria, articulação dramática. Não há dúvida 
de que o fragmentário é um dos traços da dramaturgia vicentina, que é, antes de tudo, um espetáculo de variedades com grandes atrações para distrair e atrair o público. Aliás esta marca faz com que o teatro vicentino se aproxime de umas das tendências da modernidade, onde o princípio aristotélico de linearidade é substituído pelo caráter fragmentário das cenas.

Paul Teyssier, em seus estudos sobre o teatro vicentino, destaca quatro fontes de influências:

$1^{\circ}$ ) os textos religiosos: o Antigo Testamento, o Novo Testamento, o Breviário e as Horas Canônicas;

$2^{\circ}$ ) a cultura castelhana, destacando o teatro espanhol de Juan del Encina;

$3^{\circ}$ ) o antigo teatro francês (a moralidade);

$4^{\circ}$ ) a tradição popular portuguesa transmitida pelo folclore e pela literatura oral.

Em relação às influências francesas, em primeiro lugar, algumas peças de inspiração religiosa são nomeadas pelo próprio Gil de moralidades (transposição do francês moralité). Em segundo lugar, vamos encontrar uma série de paralelismos entre os teatros cômicos francês e vicentino: certos tipos de personagens (frades devassos, alcoviteiras, fidalgos famintos, regaterias etc.), temas e cenas inteiras. Em relação aos temas e às cenas, Paul Teyssier cita uma passagem de Romagem de Agravados, em que Bastião é submetido a um exame para constatar se tem vocação ou não para ser padre, o que é uma idéia que se encontra freqüentemente no teatro francês.

Identificar-se com os gêneros medievais, tanto sacros (mistérios, moralidades e milagres), quanto profanos (farsas) não significa tomálos ao pé da letra. Pelo contrário, estes gêneros são incorporados para serem interseccionados, fazendo com que, nesta operação, o sublime e o grotesco passem a contracenar um com o outro. Na trilogia das Barcas, por exemplo, Gil Vicente apropria-se da forma das moralidades (espaço do sublime) para retratar os personagens, conforme a tradição satírica profana (espaço do grotesco). O caráter 
sublime da alegoria didático-cristã medieval do rito de passagem - onde os atos dos homens serão julgados, depois da vida, determinando o destino eterno das almas - é incorporado para contracenar com a construção caricatural dos personagens. Nada mais burlesco do que a chegada do frade pecador e libertino no Auto da Barca do Inferno. Este personagem entra em cena, acompanhado por uma mulher e segurando um escudo e uma espada. Além de todos estes adereços, incompatíveis com a figura de um membro da igreja, o personagem entra em cena cantarolando e dançando o tordião, dança muito em voga na época.

Cabe, aqui, ressaltar as fronteiras tênues que separam a farsa da comédia. A maioria dos autores, que se dedicaram ao estudo dos gêneros, considera que a distinção entre estas formas dramáticas, reside nos recursos técnicos que são utilizados para a composição do grotesco. A farsa, ao contrário da comédia, apresenta uma construção caricatural, às vezes grosseira, das personagens, exagerando, inclusive, nos contrastes. Para Erich Auerbach, a farsa é uma forma realista e cotidiana do teatro cômico, correspondendo às trovas (fabliaux) ou aos contos em versos. A característica fundamental deste gênero é a encenação das faces rasteiras e burlescas do homem, tendo como assunto preferido os ardis que as mulheres adúlteras pregam aos seus maridos. Quanto ao grotesco, Anatol Rosenfeld faz questão de grifar que este recurso deve ser interpretado como índice contundente da existência de crises profundas no social. Segundo esse autor, diante do grotesco, não podemos deixar de sentir um ligeiro estremecimento, já que estamos diante de um espetáculo descomunal do mundo, onde os valores fundamentais perderam a sua razão de ser.

É na utilização do grotesco como efeito cômico que podemos encontrar uma das pistas do sintoma ${ }^{1}$ de Gil Vicente diante do mundo

${ }^{1}$ Sintoma é aqui usado, precisamente, no sentido que Jacques Lacan deu a este termo, em sua releitura da obra freudiana. Não podemos nos esquecer que, desde Freud, um sintoma, neurótico ou não, está sempre sobredeterminado por dois sentidos: "símbolo de um conflito defunto" e símbolo de "um conflito presente" (LACAN, 1998. p.270). É a crença nos valores cristãos 
que desaba aos seus pés. Ele retrata, a partir de seus personagens, uma realidade social, onde, da nobreza ao homem do povo, passando pela igreja, temos um desfilar de figuras, que sintetizam a decadência moral: alcoviteiras, escudeiros falidos, frades libertinos, moças à procura de casamento por interesse financeiro, maridos traídos e etc.

Muito se falou do conservadorismo de Gil Vicente. Argumento, aliás, sempre utilizado para desmerecer sua obra, como se ele estivesse na corte para adular os poderosos. Ninguém foi mais crítico à sociedade de seu tempo do que Gil Vicente. Se esta crítica, como é o caso de Os Autos das Barcas, foi exercida em nome de uma moral cristã, isto é outra questão. A ironia e a corrosão são os instrumentos utilizados para denunciar uma sociedade que se constrói a partir da dicotomia entre o discurso oficial da Igreja e da Nobreza e os atos que são praticados por seus representantes. A alegoria didático-cristã aponta não só para um homem que acredita nos valores que sustentaram uma sociedade feudal, mas também para o inconformismo deceptivo de quem está assistindo à derrocada dos laços fraternos entre os homens.

Gil Vicente seria o que Walter Benjamim classifica de o dominador insatisfeito com a própria dominação. O efeito moralizante do teatro didático-religioso medieval se transforma em instrumento para denunciar a postura cínica dos homens que traem em seus atos os preceitos cristãos. Ninguém mais do que Gil Vicente representa a crise da sociedade manuelina, colocando em cena todas

que faz com que Gil Vicente se torne, através do seu teatro, um crítico da sociedade portuguesa de sua época. É neste sentido que se pode afirmar que Gil Vicente, em momento nenhum de sua obra, se contrapõe aos valores morais, que se sustentam na máxima do cristianismo: amar o próximo como se ama a si mesmo. A fraternidade, a caridade, a honestidade, o perdão e a fé em Deus ruíram. Os que estão no poder se afastaram da verdade dos evangelhos e se corromperam pelos valores mercantis e mundanos. É preciso resgatar esta verdade, que é, também, a sua verdade. E, justamente por isto, o teatro é a sua contribuição como sujeito para o resgate desta verdade. Interpretar o mundo, denunciando a sua desordem, é o modo pelo qual Gil Vicente, alienado no Outro, Deus-pai-todo-poderoso, fala do seu sintoma e se implica com esta verdade. 
as suas contradições. Ele faz com o teatro o que os cruzados fizeram com suas espadas: em nome do amor a Deus é preciso combater o mal para que a Verdade seja salva.

O motivo temático, que engendra o Auto da Índia, 1509, indica que Gil Vicente não só pressentia as bases frágeis da ascensão e da riqueza do império colonial português, mas também assistia perplexo às transformações de uma sociedade, que se orientava para uma economia monetária, colocando em xeque os antigos valores cristãos. A passagem do feudalismo agrário para o mercantilismo urbano, propiciava, cada vez mais, a tendência para práticas econômicas, tornando sem efeito as fronteiras que a sociedade medieval estabelecera entre o lucro, o juro e a usura. ${ }^{2}$ Por outro lado, as viagens marítimas, sustentáculo do comércio das especiarias, aguçavam mais ainda as contradições, na medida em que eram sustentadas por um discurso que as apresentava como se fossem a retomada da Guerra Santa. Ou seja, a cristianização do bárbaro-gentio deixou de ser um ato de fé, transformando-se em subterfúgio dos interesses político-econômicos, que visavam à construção de um império colonial. Gil Vicente, ao

${ }^{2}$ Jacques Le Goff faz questão de ressaltar a diferença, na doutrina eclesiástica da Idade Média, entre a usura e o lucro. A usura é o excedente ilícito, o excesso ilegítimo (LE GOFF, 1987. p.29). Este excesso está diretamente relacionado ao estatuto do dinheiro. A cobrança de juros só é considerada usura quando não existe produção ou transformação material de bens concretos (LE GOFF, 1987. p.18). A dádiva e a contradádiva, noções estranhas ao capitalismo, servem de parâmetro para diferenciar o lucro da usura. Diz Le Goff, citando Thomas de Chobam: "Em todo os outros contratos posso esperar um lucro (lucrum), tal como se eu te tiver dado alguma coisa posso esperar uma contradádiva (antidotum), isto é, uma réplica da dádiva (contra datum) e posso esperar receber, pois fui o primeiro a dar-te. Da mesma maneira, se te emprestei as minhas roupas ou mobiliário, posso receber um preço em compensação. Por que não se hão-de passar as coisas da mesma maneira se eu tiver emprestado o meu dinheiro (denarios meo)?" (LE GOFF, 1987. p.1819) A usura, como uma forma rapina, será violentamente condenada pela igreja medieval sendo, inclusive, identificada com o quarto mandamento: Não roubarás (Non furtum facies). 
testemunhar a extinção dos valores cristãos medievais, julga o presente a partir do passado, o que faz com que recuse as "novas idéias estéticas", advindas do humanismo renascentista, adiando, desta forma, a morte do teatro medieval.

O fato de Gil Vicente se agarrar com unhas e dentes ao passado, insistindo em fazer um teatro que ignora as novas tendências, não deixa de ser sintomático, no que diz respeito ao movimento renascentista português. Disso muito já se falou. Apontar a presença do gótico tardio no estilo manuelino é, aos olhos de muitos historiadores da arte, um modo de explicar este fenômeno. Outros identificam na presença do gótico tardio a raiz do maneirismo português, cujo representante incontestável seria a épica e a lírica camonianas. Não é o que acontece com o teatro vicentino que, de certa forma, se situa à margem da verdadeira revolução que os humanistas italianos provocaram nas artes, influenciando toda a Europa. Enquanto na corte portuguesa reinava, quase de forma soberana, o modelo teatral vicentino, Sá de Miranda (1481-1588?), poeta e humanista, depois de ter passado alguns anos na Itália, retorna a Portugal, em 1526, trazendo as novas tendências do "estilo novo". No teatro, a via de expressão do cômico não é mais a farsa e sim a comédia. Um novo gênero dramático, em língua vulgar, tendo como modelo o teatro greco-latino, inaugura o teatro italiano da Renascença. Sá de Miranda, encantado com La Mandragola(1516) de Maquiavel e com teatro de Ariosto, escreve sua primeira comédia, Estrangeiros, que estréia em Coimbra, ${ }^{3}$ no ano de 1528 . Sobre esta peça, comenta Luciana Stegagno Picchio:

"Estrangeiros", escritos em prosa, rigorosamente repartidos por cinco atos, voluntariamente aderentes aos esquemas de Plauto e Terêncio, imitando deliberadamente Ariosto e respeitando as três unidades aristotélicas, se apresentavam qual autêntico manifesto da nova escola literária. ${ }^{4}$

${ }^{3}$ Não é por acaso que a estréia desta peça é feita em Coimbra. A Corte, como destaca Luciana Stegagno Picchio, já não é o único centro cultural do País. A universidade, "transferida para Coimbra, se tem afirmado como centro de estudos humanísticos", o que levou, inclusive, à grande reforma acadêmica, realizada por ordem de D. João III, em 1537 (PICCHIO, 1969. p.114).

${ }^{4}$ PICCHIO, 1969. p.116. 
Seis anos depois da vinda de Sá de Miranda da Itália, introduzindo a estética do classicismo em Portugal, e três anos depois da estréia de sua primeira comédia, Gil Vicente encena o Auto da Lusitânia, 1532, firmando sua posição como dramaturgo que não quer saber da reviravolta que está ocorrendo nas artes de seu tempo. $\mathrm{Na}$ abertura da peça, temos a farsa dos judeus, seguida por uma fantasia alegórica, que conta a estória de amor entre Lisibéia e Portugal. Nesta versão mítica sobre a origem de Lisboa se inscreve a moralidade que encena o famoso episódio de "Todo Mundo e Ninguém”.

Em relação à farsa como gênero, José Antônio Saraiva chama nossa atenção para dois modelos: A Farsa de Inês Pereira (1523) e o Auto da Índia (1509) correspondem ao modelo dramático com intriga, nó e desenlace e o Juiz da Beira (1525) pertence ao modelo que se limita à apresentação de personagens-tipo, sem qualquer preocupação de articulá-los com a intriga.

A maioria dos personagens vicentinos se apresenta como seres humanos degradados, obstinados diante da ascensão social, do enriquecimento e da luxúria. Os que escapam desta classificação são os inocentes, ou seja, aqueles que não sabem o que fazem, como é o caso do parvo, de Inês Pereira, antes do casamento, e de Pêro Marques. Édipo também não é culpado por seus atos. Ele não sabia que estava matando seu pai nem que estava dormindo com sua mãe. Apesar das diferenças culturais, religiosas e estéticas entre Sófocles e Gil Vicente, encontramos neles o saber associado ao pecado. No caso de Gil Vicente, é o saber que transforma as personagens em agentes de uma postura cínica, tão bem descrita no comportamento político dos príncipes de Maquiavel (1513). Os inocentes, "as belas almas", são apresentados como vítimas da moral cínica que domina os laços sociais. Inês perde a inocência, quando decide casar, pela segunda vez, com Pêro Marques. Este, no final da peça, se torna vítima da aprendizagem de sua mulher. E, justamente por isto, é apresentado como marido traído, como objeto a ser ludibirado pela esperteza de sua mulher. Inês, fruto da aprendizagem de um sonho de amor desfeito, se desloca para o lado dos cínicos, e passa a integrar a trupe daqueles que sabem o que fazem. 
A farsa, como já vimos, é o gênero por excelência para mostrar as mazelas do mundo. Na construção caricatural e no uso do grotesco, os defeitos dos personagens são exagerados não só para provocar o riso, mas também para indicar o descontentamento nostálgico com a ordem social vigente. A nostalgia é o sintoma de Gil Vicente. É, através do teatro, que Gil Vicente falará do seu sintoma, alimentado pela fé e pela esperança numa nova ordem que há de vir. Seu teatro representa a ruína da ordem social vigente, em função da suposição de uma ordem anterior, onde não havia a hiância entre discurso e ato. Gil Vicente, por acreditar na função da igreja e no cristianismo, usa a farsa para denunciar a postura cínica daqueles que se comportam segundo o adágio: façam o que eu digo e não o que eu faço. O exercício da crítica sustenta a esperança na restauração da ordem em função de uma perda. Seu teatro é testemunho de um lamento em torno de um ideal que não se concretizou, encenando as ruínas de um momento histórico que usa a fé como álibi para uma política de dominação. Entre o que se apresenta sendo e o que deveria ter sido e não foi, nasce a galeria dos personagens vicentinos. O maniqueísmo é o suporte de uma alegoria-didática que utiliza o símbolo para a configuração das personagens, que se definem na superfície por qualidades morais antagônicas: bons X maus, explorados X exploradores, honestos X corruptos, etc. Entre eles, destacam-se os simplórios que, por nada saberem, são isentos da crítica vicentina. O não-dito passa a ser colocado na boca dos personagens, indicando a insatisfação com um devir que denega a fraternidade humana.

Não existe melhor exemplo desse procedimento do que a moralidade inserida no Auto da Lusitânia, onde o Bem e o Mal são personificados através de duas personagens: Todo o Mundo, um rico mercador, e Ninguém, um pobre homem. Aliás, Gil Vicente, nesta moralidade, mostra sua rejeição ao novo sistema econômico, que necessita de práticas que, por serem consideradas o exercício da usura, só eram realizadas pelos judeus. Dinarte e Belzebu são os demônios que interferem no diálogo dessas duas personagens, repetindo o que foi dito, a fim de transformar o caráter singular de uma fala em discurso dominante. 


\section{Ninguém}

Como hás nome, cavaleiro?

\section{Mundo}

Eu hei nome Todo o Mundo, e meu tempo todo inteiro sempre é buscar dinheiro, e sempre nisto me fundo

\section{Ninguém}

Eu hei nome Ninguém, e busco a consciência.

\section{Belzebu}

Esta é boa experiência:

Dinato, escreve isto Belzebu.

\section{Dinato}

Que escreverei, companheiro?

\section{Bezlebu}

Que Ninguém busca a consciência, e Todo o Mundo dinheiro. ${ }^{5}$

Este diálogo para ser compreendido deve ser inscrito nos princípios morais do cristianismo medieval, onde o homem para conseguir a salvação tinha que escolher entre a bolsa e a vida eterna. O usurário impenitente, aquele que não resistiu a tentação demoníaca do dinheiro, será condenado ao fogo perpétuo do Inferno.

A esperança, fruto de um ideal ao qual Gil Vicente não renuncia, se torna cada vez mais distante e impossível de se concretizar. Os efeitos cômicos das cenas, que provocam o riso, refletem a ironia do autor consigo mesmo. A comicidade se torna, então, o instrumento para ironizar sua nostalgia diante da ordem perdida. $O$ grotesco e o cômico divertem um público que não se vê retratado nas cenas, porque o que está sendo representado é sempre o outro. É justamente porque não há identificação consigo mesmo que as gargalhadas explodem diante dos mal-entendidos e das situações

\footnotetext{
${ }^{5}$ VICENTE (Difel), 1975. p.317.
} 
ridículas. O riso, provocado pelas encenações grotescas, é efeito de uma construção que apresenta os personagens como figuras que, por sua generalidade, apontam para um universal que nega o particular.

\section{Auto da Barca do Inferno (1517): o retorno do recalcado no amor divino}

Paul Teyssier considera esta peça, junto com os autos da Barca do Purgatório (1518) e da Barca da Glória (1519) as obras-primas de Gil Vicente. Para ele, é um equívoco designar essas peças de "trilogia das Barcas". Em primeiro lugar, foram escritas e encenadas em anos diferentes. Em segundo lugar, apesar do tema comum - o julgamento depois da morte -, o título Barca do Purgatório seria impróprio, porque só há duas barcas: a do Inferno e a do Paraíso. O Purgatório é, apenas, a margem do rio, onde os mortos condenados ficarão até serem admitidos no paraíso, depois de se redimirem dos seus pecados.

A única personagem que, apesar de ser condenada, não irá embarcar na barca do Inferno, porque será levada a reboque, é o judeu. Paul Teyssier considera que esse procedimento simboliza a exclusão dos judeus na sociedade cristã portuguesa. Uma exclusão estarrecedora, que espanta por sua violência radical. O judeu, mesmo depois de morto e condenado ao fogo eterno do Inferno, nem assim pode se misturar com os pecadores cristãos. Jacques Lacan, no Seminário 20, Mais, ainda, afirma que o verdadeiro amor desemboca no ódio. O adjetivo "verdadeiro" se refere à Verdade que se sustenta no três: Pai, Filho e Espírito Santo. O dogma da Santíssima Trindade se sustenta na incomensurabilidade do amor divino. Jesus Cristo veio à terra para salvar os homens e ofereceu como prova de amor o sacrifício de seu corpo, que é flagelado e crucificado. Primeiro o assassínio, depois a anulação do ato realizado, que fica sem efeito com a ressurreição. Cristo cumpriu sua missão por amor, não aos homens, mas ao Pai. Quem ama todos os homens e exige que eles se amem entre si é Deus. "Amai o próximo como a ti mesmo" diz o 
preceito cristão. Como amar um outro como se fosse eu mesmo sem eliminar a diferença e instaurar o império da igualdade? Como impor a igualdade sem usar a força e o avesso simétrico do amor, que é o ódio? Como interpretar esta cena do judeu excluído, mesmo depois de morto, da companhia dos cristãos pecadores? Quem melhor do que o judeu para simbolizar a exclusão do estranho? O recalcado, ou seja, aquilo de que não se quer saber e, justamente por isto, é mantido afastado da consciência, retorna, porque o inconsciente insiste e ignora a vontade egóica de não querer saber. O retorno do recalcado só pode comparecer na fala que escapa à intencionalidade. Será que esta cena aponta para o pressentimento da perseguição que viria a se instalar com o Santo Ofício? Sem dúvida, a Inquisição retirou o véu do amor ao próximo, revelando a outra face deste amor, que é o ódio à alteridade. Disto Gil Vicente não quer saber, porque se agarra à ilusão de que a fraternidade entre os homens depende do preceito cristão do amor. Um amor que se marcou na história por papéis bastante demarcados. De perseguidos pelos romanos a perseguidores dos gentios, dos bárbaros, dos judeus, etc. Como continuar insistindo em acreditar no amor ao próximo? Só não querendo saber do fundamento de segregação que regula esse preceito. Só lamentando o que nunca aconteceu, mas poderia ter acontecido, se...

A desilusão com a Promessa de Fraternidade é sublimada pela via da criação de um teatro que se constrói das cinzas do próprio cristianismo. A raiz do desconcerto do mundo está nos homens e não na concepção do amor ao próximo. Gil Vicente, em vez de se tornar um caçador de hereges, ou um melancólico, suspirando pelos cantos a dor da frustração, não pára de trabalhar, não pára, até que os rumores da Inquisição se tornam uma realidade, surge a instituição do Santo Ofício, com seus tribunais, salas de torturas, condenações à morte, listas de censurados etc. 


\section{Auto da Índia (1509): a desmistificação das viagens}

A versão do discurso oficial sobre os empreendimentos marítimos portugueses se contrapõe à realidade dos bastidores, revelando o enriquecimento dos nobres a custa da aspiração de ascensão social dos infortunados plebeus. Eis o depoimento do personagem que, ao regressar, confessa a frustração de todas as suas esperanças depositadas na viagem:

\section{Marido}

Fomos ao rio de Meca, pelejámos e roubámos, e muito risco passámos à vela e à arvore seca

\section{Ama}

Porém vindes muito rico

\section{Marido}

Se não fora o capitão

Eu trouxera o meu quinhão

Um milhão, vos certifico. ${ }^{6}$

Esta versão vicentina se aproxima da fala profética do Velho de Restelo (Os Lusíadas). Pela voz deste personagem, Camões denuncia que a viagem do Gama não está a serviço da Fé, mas é motivada pela glória de mandar, pela vã cobiça e pela Fama.
Ó glória de mandar, ó vã cobiça
Desta vaidade a quem chamamos Fama,
Ó fraudulento gosto, que atiça
C'ũa aura popular, que honra se chama,
Que castigo tamanho e que justiça
Fazes no peito vão que muito te ama!
Que mortes, que perigos, que tormentas,
Que crueldades neles experimenta!

${ }^{6}$ VICENTE (Publicações Europa América), 1975. p.50-51. 
Dura inquietação d'alma e da vida Fonte de desamparos e adultérios, Sagaz consumidora conhecida De fazendas, de reinos e de impérios:

Chamam-te ilustre, chamam-te subida, Sendo digna de infames vitupérios;

Chamam-te Fama e Glória soberana, Nomes com quem se o povo néscio engana. ${ }^{7}$

A revelação dos interesses políticos e mercantis, tanto do ponto-de-vista subjetivo quanto governamental, coloca em cena as vozes recalcadas por uma retórica que expressou o sonho de todos os portugueses que acreditaram na formação de um Novo reino que edificaria o aumento da Cristandade...

Tanto Gil Vicente quanto Camões acreditaram no processo de evangelização das viagens. Paul Teyssier nos lembra que, nesta peça, a interpretação de Gil Vicente é radicalmente diferente da que apresenta em Exortação da Guerra: Santo Deus! O homem que escreveu este auto é o mesmo Gil Vicente que na Exortação da Guerra convoca os portugueses a mobilizarem-se para a cruzada do Ultramar? ${ }^{8}$ Quanto a Camões, basta confrontar a Dedicatória com a fala do Velho do Restelo e com o Epílogo, em Os Lusíadas, para encontrarmos a exaltação e o desencanto com a viagem de Vasco da Gama.

\section{Dedicatória}

Vós, poderoso Rei, cujo alto império

O Sol, logo em nascendo, vê primeiro;

Vê-o também no meio do Hemisfério,

E quando desce o deixa derradeiro;

Vós, que esperamos jugo e vitupério

Do torpe Ismaelita cavaleiro,

Do Turco oriental e do Gentio

Que inda bebe o licor do santo Rio; ${ }^{9}$

\footnotetext{
7 CAMÕES, 1979. p.218-219. Canto 4. Estrofes 95-96.

8 TEYSSIER, 1982. p.68.

${ }^{9}$ CAMÕES, 1979. p.61. Canto I, estrofe 8.
} 


\section{Epílogo}

Nô mais, Musa, nô mais, que a Lira tenho

Destemperada e a voz e enrouquecida,

E não do canto, mas de ver que venho

Cantar a gente surda e endurecida. ${ }^{10}$

É lógico que iremos encontrar entre os críticos considerações que tentam compreender estas contradições. Paul Teyssier, por exemplo, alega que esta peça foi escrita com a finalidade de apoiar a política real, porque, em 1514, o Papa atribuiu ao rei de Portugal as terças das dízimas das catedrais, igrejas e mosteiros do reino, o que provocou uma reação por parte da igreja, que se considerou lesada nos seus interesses financeiros. Alguns críticos, em relação a Os Lusíadas, argumentam, referindo-se à Dedicatória, que ele pretendia receber um soldo do rei, que lhe permitisse viver com dignidade. Por causa disso, não só dedicou Os Lusíadas a D. Sebastião, mas também apresentou os empreendimentos marítimos como verdadeiras cruzadas. O fato é que, além de colocar na fala do Velho Restelo uma versão, que entra em contradição com a versão da Dedicatória, irá construir duas visões antagônicas do rei D. Sebastião e de sua corte. Na Dedicatória, o rei é apresentado como certíssima esperança / De aumento da pequena Cristandade, / Maravilha Fatal da nossa idade. ${ }^{11}$ Já no penúltimo canto, D. Sebastião é retratado como aquele que ignora seu povo e é cercado por aduladores, que alimentam sua vaidade real. Em vez de ficarmos supondo as motivações subjetivas destas contradições, devemos levar em conta a frustração humana, experiência que está diretamente ligada à decepção com o fracasso das esperanças. Tanto Gil quanto Camões se desiludem com uma nação dilacerada entre, por um lado, os interesses privados dos seus dirigentes e, por outro lado, uma população esquecida e ludibriada pela hiância que se abre entre o que se diz e o que se faz. Independente dos motivos

\footnotetext{
${ }^{10}$ CAMÕES, 1979. p.218-219. Canto 4. Estrofes 05-96.

${ }^{11}$ CAMÕES, 1979. p.61. Canto 1. Estrofe 6.
} 
subjetivos, até porque esses foram para sempre enterrados com a morte desses autores, a literatura para um e o teatro para outro tiveram para eles a função de sublimar os sonhos desfeitos. O grotesco e o sublime, separados ou misturados, foram os caminhos que encontraram para dizer o que acontecia por detrás das cortinas de um palco que encenava uma ficção com valor de verdade. Suas ficções vêm se contrapor à grande ficção com que se comemoram os 500 anos de uma história, ligados à descoberta de um Mundo Novo chamado Brasil.

\section{Farsa de Inês Pereira (1523) e a desmisticação do sonho de amor}

Esta peça é considerada pela maioria dos estudiosos de Gil Vicente a mais elaborada, no que diz respeito à integração entre as cenas pela ação. Esta abordagem não deixa de apontar para uma valorização estética, que se fundamenta no conceito aristotélico de verossimilhança.

Saber falar de amor, fazer versos, cavalgar e trovar apontam para a imagem de um amante, emoldurado pelos hábitos da aristocracia. Este era o modelo masculino que fazia com que as donzelas suspirassem e sonhassem com belas e felizes estórias de amor. Inês, como representação das mulheres que não pertencem à aristocracia, mas sonham vir a freqüentar o palácio, entra em conflito com sua mãe, tal qual as donzelas das cantigas de amigo. Entretanto, cabe ressaltar uma diferença. A mãe de Inês, ao contrário das mães das cantigas dos trovadores, não está preocupada em zelar pela moral (virgindade) de sua filha, mas em assegurar "um futuro melhor", através de um "bom casamento".

A estória de Inês é construída de forma a possibilitar uma grande virada, que irá convergir para o ditado popular que serve de argumento a peça (mais quero asno que me leve que cavalo que me derrube). Isso aparece, claramente, na fala de Inês a Lianor Vaz: 


\section{Inês}

Andar! Pero Marques seja!

Quero tomar por esposo

quem se tenha por ditoso

de cada vez que me veja.

Por usar de siso mero

asno que me leve quero,

e não cavalo folão.

Antes lebre que leão;

antes lavrador que Nero. ${ }^{12}$

A transformação do amante - de galante escudeiro a marido tirânico - desmistifica o final feliz dos sonhos de amor, tão bem tecidos e prometidos em Amadis de Gaula, e serve de aprendizagem a Inês, que sofre uma transformação moral, tornando-se semelhante à alcoviteira Lianor Vaz.

Não deixa de ser curioso, embora coerente com a moral cristã, o modo pelo qual o sexual se inscreve. Desvinculado do amor e associado à concupiscência, torna-se o recurso cômico por excelência, através de equívocos que comparecem na fala dos personagens, introduzindo, desta forma, o grotesco. O duplo sentido do verbo conhecer (ser conhecido de, e ter relações sexuais com), no diálogo entre a mãe de Inês Pereira e Lianor Vaz, além de provocar o riso, ridiculariza o comportamento devasso de alguns representantes do clero.

Gil Vicente não perdoa os integrantes da Igreja que se comportam na mais absoluta discordância com os valores cristãos. O clérigo e, no final da peça, o ermitão são personagens encaixados na trama para explicitar a decadência das instituições religiosas que, cada vez mais, perdem a sua função. O ermitão, o homem santo das novelas de cavalaria, se transforma em servo de Cupido, induzindo Inês ao adultério. Utilizando-se da paródia, Gil superpõe dois textos na fala do ermitão: o discurso religioso e o da sedução. O amor a Deus se declina para dar lugar ao desejo pelas mulheres.

12 VICENTE (Publicações Europa América), 1975. p.124. 


\section{Ermitão}

Y acabando

las horas, todas llorando, tomo las cuentas una a una, con que tomo a la Fortuna cuenta del mal en que ando, sin esperar paga alguna.

$\mathrm{Y}$ ansí, sin esperança de cobrar lo merecido, sirvo alli mis dias Cupido con tanto amor sin mudança que soy su santo escogido. ${ }^{13}$

O duplo sentido da palavra cuentas (contas do rosário e prestar contas, já que o destino fez com que ele se apaixonasse por Inês, sem esperança de ser correspondido) cria um qüiproquó em cena. Tanto o público quanto a personagem Inês decodificam a fala do ermitão como uma declaração de amor, enquanto o ingênuo Pêro Marques acredita que ele está pedindo esmola sem esperança de recebê-la. A resposta à demanda do ermitão dada por Inês enfatiza a comicidade da cena:

\section{Inês}

Tomai a esmola, padre, lá, pois que Deus vos trouxe aqui.

\section{Ermitão}

Sea por amor de mi vuestra buena caridad.

Deo gratias! mi señora, la limosna mata el pecado; pero vos tenéis cuidado de matarme cada hora. ${ }^{14}$

Na resposta ambígua de Inês (tomai lá a esmola / tomai a esmola lá), o público imediatamente apreende sua intenção,

\footnotetext{
13 VICENTE (Publicações Europa América), 1975. p.127.

${ }^{14}$ VICENTE (Publicações Europa América), 1975. p.128.
} 
provavelmente rindo não só da astúcia da personagem, mas também da ingenuidade de seu marido, que não percebe nada. Pêro Marques se apresenta aos olhos do público como o asno do ditado que dá origem à farsa. Na cena em que o ermitão agradece a esmola, Gil Vicente, apropriando-se da expressão latina Deo gratias!, identificada com o registro religioso do discurso, coloca esta expressão na fala do ermitão, seguida do adágio popular a esmola mata o pecado. A ambigüidade, produzida por esta articulação, provoca o riso, na medida em que o significado do provérbio de que a esmola dada aos pobres atenua os pecados dos homens diante da justiça divina passa a ter outro sentido, ou seja, de que a satisfação mata o amor. Este sentido se explicita, quando o ermitão jura a Inês que seu amor será eterno.

A cortesia e as "leis do amor", seguidas pelos trovadores nas cantigas de amor, comparecem como discursos de sedução e, como tais, são utilizados como instrumentos para conquistar as mulheres ou para conseguir uma esposa. Da inspiracão à retórica, temos a dissolução do amor cortês, deixando rastros nas aspirações das donzelas, que sonham em ser amadas e cortejadas tal qual a Dama, nas cantigas de amor. Entretanto, neste gênero, trata-se de um amor impossível, onde a Dama, mesmo não correspondendo ao amor do trovador, exigia e recebia devoção e fidelidade. Esses tempos não existem mais. Aliás, só existiram como ficção na escrita dos poetas. Mas não podemos deixar de ler o lamento de uma voz entristecida que se queixa da inexistência do amor, quer seja ao próximo, a Deus ou às mulheres.

Gil Vicente insiste na apresentação das alcoviteiras, dos casamenteiros, das donzelas aspirantes à ascenção social pelo casamento, das mulheres adúlteras, dos homens que querem uma esposa para subjugar. Enfim, um mundo, sob a sua ótica, desordenado, um mundo corrompido pelos homens que se afastaram de Deus e do cristianismo. Assim, por mais paradoxal que seja, Gil Vicente, o teatrólogo oficial da corte, é quem melhor retrata as mazelas da sociedade portuguesa da primeira metade do século XVI. Escrevendo, 
montando e dirigindo suas peças, diz o seu sintoma. Nas entrelinhas da fala de cada personagem, deixa rastros de um sujeito dividido entre o que foi supostamente perdido e o que poderia ser reencontrado. A frustração diante de um presente desordenado é sublimada por um dizer que se tece fio por fio na esperança de um amor que fez com que Cristo sacrificasse seu corpo e sua vida. Um amor que falha no presente, matando a esperança de um futuro.

\section{Referências Bibliográficas}

AUERBACH, Erich. Introdução aos estudos literários. São Paulo: Cultrix, 1970.

BENJAMIM, Walter. Origem do drama barroco alemão. São Paulo: Brasiliense, 1984.

CAMÕES, Luís de. Os lusiadas. Org. António José Saraiva. Rio de Janeiro: Livraria Padrão, 1979.

LACAN, Jacques. O seminário. Livro 20. Mais, ainda. Rio de Janeiro: Zahar, 1982.

LACAN, Jacques. Escritos. Rio de Janeiro, Zahar, 1998.

LE GOFF, Jacques. A bolsa e a vida. Lisboa: Teorema, 1987.

MICHAËLIS DE VASCONCELOS, Carolina de. Notas vicentinas. In: Revista Ocidente, Lisboa, 1949.

PICCHIO, Luciana Stegagno. História do teatro português. Lisboa: Portugália, 1969.

REBELLO, Luiz Francisco. O primitivo teatro português. Lisboa: Instituto de Cultura e Língua Portuguesa. (Col. Biblioteca Breve). RECKERT, Stephen. Espírito e letra de Gil Vicente. Vila da Maia: Imprensa Nacional - Casa da Moeda, 1983. (Col. Temas Portugueses).

ROSENFELD, Anatol. Texto/ contexto. São Paulo: Perspectiva, 1969. (Col. Debates 7). 
SARAIVA, António José. Gil Vicente e o fim do teatro medieval. Lisboa: 1942.

TEYSSIER, Paul. Gil Vicente- o autor e a obra. Lisboa: Instituto de Cultura e Língua Portuguesa / Ministério da Educação e das Universidades, 1982. (Col. Biblioteca Breve).

VICENTE, Gil. Obras primas do teatro vicentino. 2.ed. Org. Segismundo Spina. São Paulo: Difel, 1975.

VICENTE, Gil. Sátiras sociais. Ed. anotada. Intr. e notas Maria de Lourdes Saraiva. Mira-Sintra: Publicações Europa-Améria, 1975.

\section{Resumo}

Este artigo é uma leitura do teatro de Gil Vicente, o organizador dos espetáculos da corte portuguesa, na primeira metade do século XVI. A dicotomia entre o dizer e o agir dos representantes da Igreja e da Nobreza é criticado, pela via da alegoria didáticocristã, apontando não só para sua crença nos valores cristãos, mas também para sua desilusão à derrocada do mundo. Nas falas dos seus personagens diz seu sintoma: um sujeito dividido entre o que foi supostamente perdido e o que poderia ter sido ser reencontrado. Assim, a frustração, em vez de conduzir à melancolia, é sublimada pela via da sátira, onde o grotesco tem a função de apresentar o esfacelamento da dignidade humana.

\section{Abstract}

This article is a view on Gil Vicente's theatre, the responsible for the representation in the Portuguese court, in the first half of XVI century. The dicotomy between words and actions of the representatives of clergy and nobility is criticized through a didatic and christian regard, focusing on his beliefs in christian standards but also revealing the delusion and the failure of the world. His symptons are shown on the lines of his characters: the posture of someone divided between what had been lost and what could be found. Thus, his frustration, instead of leading him to melancholy, is sublimed and the grotesque, then, represents the ruin of human dignity. 